Research Article

\title{
Deformation Forecasting of Surrounding Rock Mass Based on Correlation between Frequency and Fracture Scale of Microseismicity
}

\author{
Peiwei Xiao, ${ }^{1}$ Bo Qian, ${ }^{2}$ Peng Jiang, ${ }^{2}$ Nuwen Xu $\left(\mathbb{D},{ }^{2}\right.$ and Biao $\mathrm{Li}^{3}$ \\ ${ }^{1}$ China Guodian DaDu River Hydropower Development Co., Ltd., Chengdu, Sichuan 610016, China \\ ${ }^{2}$ State Key Laboratory of Hydraulics and Mountain River Engineering, College of Water Resource and Hydropower, \\ Sichuan University, Chengdu, Sichuan 610065, China \\ ${ }^{3}$ School of Geoscience and Technology, Southwest Petroleum University, Chengdu, Sichuan 610500, China
}

Correspondence should be addressed to Nuwen Xu; xunuwen@scu.edu.cn

Received 6 April 2018; Accepted 6 June 2018; Published 10 July 2018

Academic Editor: Hang Lin

Copyright (C) 2018 Peiwei Xiao et al. This is an open access article distributed under the Creative Commons Attribution License, which permits unrestricted use, distribution, and reproduction in any medium, provided the original work is properly cited.

\begin{abstract}
The macroscopic deformation and failure of engineering rock mass may occur as a result of evolution and breakdown of its internal microfracture. Therefore, the macroscopic state of rock mass can be obtained from fracture scale of microfracture in real time. To assess instability and predict macroscopic deformation and failure of engineering rock mass, a time-frequency analysis technique based on $\mathrm{S}$ transform was proposed to investigate microseismic waveform and reveal the correlation between macroscopic deformation failure and microseismic frequency characteristics of engineering rock mass in combination with fracture scale. To minimize the influence of external factors on parameters calculated, a significant amount of microseismic data from three large-scale hydropower projects in southwestern China was collected as the statistical sample. The analysis of correlation between fracture scale and frequency characteristics of microseismic events was carried out based on the statistical sample. Combining with microseismic data and multipoint extensometers in the underground powerhouse of the Houziyan hydropower station, engineering verification was conducted. The result shows that the high-frequency components decrease and microseismic signals display low-frequency characteristic as the fracture scale increases; the microseismic high-frequency components decreased at first and then increased during the deformation process of surrounding rock mass, and the frequency of microseismic events shifts from high band to a lower one before deformation.
\end{abstract}

\section{Introduction}

The occurrence and development of rock microfracture release energy in the form of elastic waves, that is, acoustic emissions (AEs) or microseismicity (MS). Researches show that each AE or MS contains abundant seismic source information. The analysis of AE/MS can reveal the evolution of the cracks occurred inside the rock masses and then serve as the judgment basis for the internal damage of the rock masses [1-3].

The analysis methods of AE/MS include the parameters analysis method and waveform analysis method [4]. Parameters analysis method analyzes the source characteristics by statistical parameters of the signals, such as event rate, number of events, energy rate, and $b$-value, which are widely used in the experimental study of AE. Zhang et al. [5] studied the $\mathrm{AE}$ characteristics of rock failure under uniaxial multilevel loadings by statistical parameters of the signals, such as AE event rate, number of events, and energy rate. Li et al. [6] revealed the relationship among number of AE events, event rate stress, and the time of uniaxial compression experiment. $\mathrm{Li}$ et al. [7] found the changing trend of the $b$-value of AEs and their spatial distribution of the fractal value with stress level in the processes of rock failure under uniaxial loading. The researches above have made significant progresses in the mechanism of rock failure, but these parameters only describe a single characteristic of the signal, providing insufficient information about the source 
characteristics and making great casualness in the choice of parameters $[4,8]$. Waveform analysis method uses signal processing methods to analyze the recorded waveform in time domain and reveals the seismic source information. The AE/MS signal can be defined as an instantaneous elastic wave [5]. Waveform analysis method can thus reflect the failure information of rock mass in real time. In the propagation process, the amplitude and duration of the waves are uncertain due to the attenuation, superposition, and interference. However, the frequencies of the waveforms still keep intrinsic characteristics and uniqueness [9] and are more stable [10]. Different frequency characteristics can reflect the different failure processes within the rock mass [11]. Some scholars have conducted extensive studies on the frequency characteristics of AE signals of rock. The indoor rockburst test of limestone has been conducted by $\mathrm{He}$ et al. [12] to study the frequency characteristics of AE signals before the occurrence of rockbursts. Lu et al. [13] analyzed the frequency-spectrum evolvement rule of AE signals in the entire processes from deformation to fracture by testing the compound coal-rock samples obtained from the Sanhejian coal mine. Li et al. [14] studied the AE frequency characteristics of four kinds of rock under seepage and without seepage by the indoor uniaxial compression experiment. The frequency characteristics of signals in earthquake and MS monitoring are also concerned by researchers. Neuberg et al. [15] proposed the use of low-frequency earthquakes for volcanic eruption prediction by studying low-frequency earthquakes in volcanic earthquakes and their induced mechanisms. By analyzing the MS monitoring signals prior to and after rockburst, Lu et al. [16] pointed out that the frequency spectrum of the picked-up signals changed from multipeak to single peak before rockburst and the lowfrequency component of signals increased significantly. It is also suggested that the low-frequency phenomenon can be used to predict rockburst. The time-frequency analysis of rockburst and blasting vibration signals in mine MS monitoring have been conducted by Zhao et al. [17] to identify the different waveforms. The researches above mainly focus on single-frequency characteristics. However, few studies have been done on seismic source mechanism combining seismic source parameters and frequency characteristics of MS events obtained from engineering rock mass.

The present study adopts the time-frequency analysis technique based on $\mathrm{S}$ transform to process a significant amount of pickup waveforms of MS events obtained from three hydropower projects in southwestern China. The correlation between source fracture scale and frequency characteristics of MS events was analyzed. The evolution regularity of MS signals frequency during the surrounding rock mass deformation was carried out compared with the results of the multipoint extensometers in the region of MS events concentration. Some reference can be provided for the stability analysis and hazards prediction of engineering rock mass.

\section{Waveform Analysis Method}

The waveform analysis methods such as fast Fourier transform (FFT) [18], short-time Fourier transform (STFT)
[19], and wavelet transform (WT) [20] are commonly used in the signals of indoor AE and on-site MS monitoring [4]. FFT is a conversion tool to transform signals from time domain to frequency domain, but it does not have localization ability in time domain and cannot accurately describe the frequency characteristics of nonstationary signals. The STFT can analyze the signals in the time-frequency domain under the selected window function and time width, but its window width is fixed. Therefore, it is still not able to overcome the limitation of FFT in the nonstationary signals analysis, and the choice of window function and analysis time width plays a significant role on the result of signals analysis. The WT is to decompose the signals at different scales by the selected wavelets function, and it can decompose nonstationary signals. However, the WT decomposes one-dimensional signals into time-scale domains rather than time-frequency domains, which cannot provide intuitive time-frequency characteristic. Moreover, the selection of wavelet function and analysis scale has a great influence on the analysis result, resulting in the limitation of WT in time-frequency analysis of MS signals.

$\mathrm{S}$ transform (ST) is a time-frequency analysis method proposed by geophysicist Stockwell in 1996 [21]. It can be defined as

$$
S(\tau, f)=\int_{-\infty}^{\infty} h(t) \frac{|f|}{\sqrt{2 \pi}} e^{-\left((\tau-t)^{2} f^{2} / 2\right)} e^{-i 2 \pi f t} d t,
$$

where $\tau$ is the time, which controls the position of the window function on the time axis, $h(t)$ is the analysis signals, $f$ is the frequency, and $S(\tau, f)$ is the ST-time spectrum matrix after transformation.

ST can be written in the form of Fourier spectrum $H(f)$ :

$$
S(\tau, f)=\int_{-\infty}^{\infty} H(\alpha+f) e^{-\left(2 \pi^{2} \alpha^{2} / f^{2}\right)} e^{i 2 \pi \alpha \tau} d \alpha \quad f \neq 0
$$

With regard to discrete signals, Fourier spectrum can be obtained by the following formula:

$$
H\left[\frac{n}{N T}\right]=\frac{1}{N} \sum_{K=0}^{N-1} h[k T] e^{-(i 2 \pi n k / N)}
$$

where $k=0,1, \ldots, N-1$ represents discrete time points, $N$ is the discrete signal length, and $T$ is the sampling time interval.

For discrete signals, assuming $f=n / N T, \tau=j T$, the $S$ transform of the final discrete signal can be expressed as

$$
S\left(j T, \frac{n}{N T}\right)=\sum_{m=0}^{N-1} H\left[\frac{m+n}{N T}\right] e^{-\left(2 \pi^{2} m^{2} / n^{2}\right)} e^{(i 2 \pi m j / N)} \quad n \neq 0 .
$$

Compared with STFT, ST overcomes the defect of window time width invariability and can self-adaptively adjust the analysis time width according to variation of frequency. ST can provide intuitive time-frequency characteristics without selecting window functions and analysis scales [19-21]. Owing to these advantages, ST has been widely used in time-frequency analysis of signals. In the present study, ST time-frequency analysis technology is adopted for MS signals waveform analysis, which can provide a new idea for waveform analysis. 


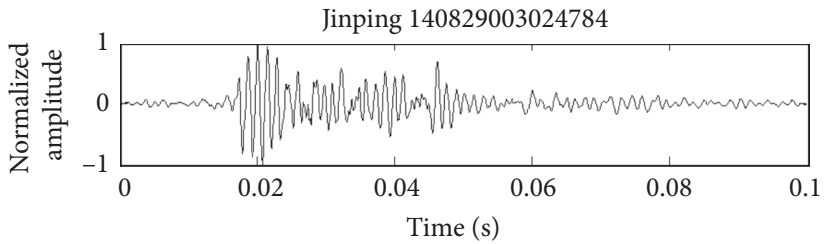

(a)

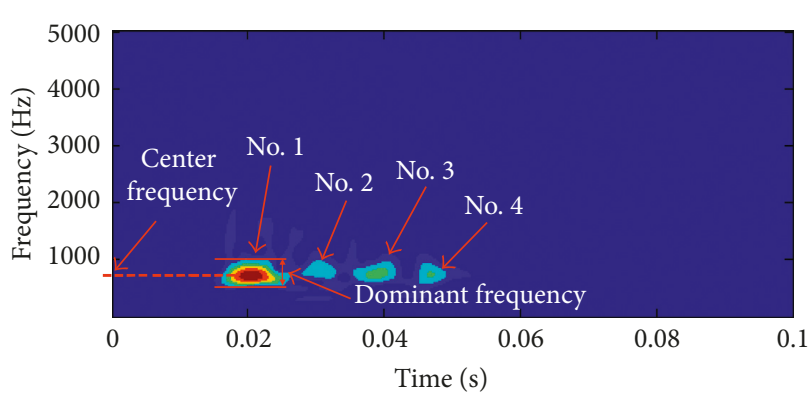

(b)

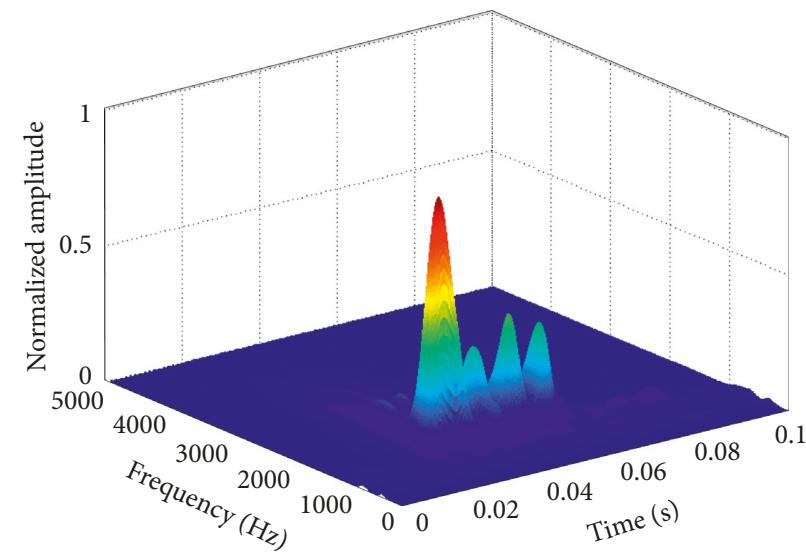

(c)

FIGURE 1: Results of MS signals after ST: (a) the time-domain waveform of MS signals, (b) time-frequency spectrum, and (c) time-frequency amplitude spectrum.

TABLE 1: Statistical sample of research objects.

\begin{tabular}{|c|c|c|c|}
\hline Research objects & & Statistical time $(\mathrm{d})$ & Number of MS events \\
\hline The left bank slope of the Jinping & Excavation & 91 & 300 \\
\hline First-stage project & Impoundment & 82 & 172 \\
\hline The underground powerhouse of the Houziyan project & & 92 & 347 \\
\hline The underground powerhouse of the Baihetan project & & 51 & 267 \\
\hline
\end{tabular}

The MS signals are transformed by ST as shown in Figure 1, in which the amplitude is normalized amplitude. Figure 1(a) shows the time-domain waveform of MS signals. Figures 1 (b) and 1(c) are the time-frequency spectrum and time-frequency amplitude spectrum of the signals, respectively. The MS signal frequency parameters have been marked in Figure 1(b). The dominant frequency is the frequency band which high-amplitude part of the timefrequency distributes, and the center of the dominant frequency band is the center frequency.

\section{Correlation between Fracture Scale and Frequency Characteristics of MS Signals}

3.1. Processing of MS Monitoring Data. The elastic waves released from rock fractures will suffer from attenuation due to the complexity of the media in the propagation processes. Thus, there are some deviations in the calculation of seismic source parameters of single MS event. However, when the number of statistical samples increases, the differences caused by such attenuation and manual handling will be minimized as much as possible [22]. In order to minimize the influence of attenuation in the propagation of MS signals, the waveforms with the largest amplitude channels are selected for waveform analysis. According to the above reasons, the relationship between fracture scale and frequency characteristics of picked-up signals is statistically analyzed based on the abundant MS data obtained from the left bank slope of the Jinping firststage hydropower station during excavation [23] and impoundment [24], the underground powerhouse of the Houziyan hydropower station $[25,26]$, and the underground powerhouse of the Baihetan hydropower station [27]. The numbers of statistical samples for each research object are shown in Table 1.

3.1.1. Fracture Scale. The MS monitoring systems produced by ESG Corporation, Canada, are adopted for each research object in Table 1. Based on the assumption of ring fault 
TABle 2: Frequency parameters of the MS event in Figure 1(b).

\begin{tabular}{lccr}
\hline Component & Center frequency $(\mathrm{Hz})$ & Dominant frequency \\
& & Origin $(\mathrm{Hz})$ & 549 \\
No. 1 & 729 & 679 & 989 \\
No. 2 & 819 & 599 & 1009 \\
No. 3 & 759 & 539 & 999 \\
No. 4 & 749 & 989 \\
\hline
\end{tabular}

plane, the source fracture zone is equivalent to a disk with a radius of $r$, which represents the rupture scale at the focal point, namely, seismic source radius $[28,29]$. MS monitoring system can effectively capture microfractures prior to macroscope deformation and failure of rock mass. The seismic source radius of MS events will show an increasing trend before the rock mass deformation and failure [30]. Therefore, the variation of seismic source radius can reflect some characteristics of macroscope deformation and failure of rock mass. However, the calculation of seismic source radius may be inaccurate due to attenuation and superposition of signals and artificial waveform processing, in particular, when the seismic source radius of MS events in short-time periods and small areas are selected for predicting the deformation and failure of rock mass. More stable frequency parameters of MS signals are used as early warning indicators in the present study. The prediction may be realized through establishing the relationship between signal frequency and deformation and failure of rock mass based on the seismic source radius.

The Madariaga model [29] is used to calculate the seismic source radius parameters. Field observations at the Strathcona mine in Canada show that compared to the Brune model [28], the calculated value using the Madariaga model is more suitable to practical engineering [31]. Its expression is

$$
r_{0}=\frac{K_{c} c}{2 \pi f_{c}}
$$

where $K_{c}$ is a constant determined by the seismic source model and is a function of the angle between the perpendicular of the fault plane and the source-sensor ray. When the fault plane is undetermined, $K_{c}=2.01$ for the $\mathrm{P}$ wave and $K_{c}=1.32$ for the $S$ wave. $c$ is the velocity of the $\mathrm{P}$ wave or $S$ wave in the seismic source region, and $f_{c}$ is the corner frequency. Its formula [32] is

$$
f_{c}=\frac{1}{2 \pi} \sqrt{\frac{\int_{0}^{\infty} V^{2}(f) d f}{\int_{0}^{\infty} D^{2}(f) d f}},
$$

where $V^{2}(f)$ and $D^{2}(f)$ are the velocity power spectrum and displacement power spectrum of the particle, respectively.

3.1.2. Waveform Processing. The ST time-frequency analysis technique can convert the one-dimensional signals into the time-frequency spectrum in the time-frequency domain and describe the temporal variation rule of the signal frequency. The energy of the MS signal is usually distributed in multiple frequency bands, and the ST technique can accurately distinguish the frequency components contained in the MS pickup signals. For instance, a MS event and its time-frequency spectrum based on the ST technique at the left bank slope of the Jinping first-stage hydropower station during impoundment at 0:30 on August 29, 2014, are shown in Figures 1(a) and 1(b). The four highlighted areas in the time-frequency spectrum reflect that the waveform mainly contains four frequency components. The main frequency ranges of the four regions are calibrated in the time-frequency domain, and the center frequency of each region are calculated as shown in Table 2.

The MS signals of each engineering project in Table 1 are processed by the abovementioned method. Seven hundred and ninety-eight, 641, 855, and 495 frequency samples are obtained for the Jinping first-stage project during excavation and impoundment, Houziyan project, and Baihetan project, respectively.

3.2. MS Monitoring Data Analysis. As we know, AE/MS signals with different fracture scales have different frequency ranges [33]. With regard to natural earthquake, large-scale deformation and failure occur in large-scale rock mass under the action of the geological structure. The frequencies of seismic signals are distributed in low-frequency bands. Under laboratory conditions, AE frequencies of rock samples are usually distributed in high-frequency bands. Ohnaka [34] and Haskell [35] found the relationship between the frequency of $\mathrm{AE}$ signals and its crack length as follows:

$$
f \sim \frac{1}{[T+(c / v)(1-(v / \beta) \cos \theta)]}
$$

where $T$ is the time in which the crack closes, opens, or slides; $c$ is the length of crack; $v$ is the speed in which the crack generates; $\beta$ is the corner frequency of the elastic wave in which the crack generates; and $\theta$ is the angle between the propagation direction of the signal and the crack surface. When $\theta$ is $\pi / 2$, (7) can be simplified as

$$
f \sim \frac{1}{T+(c / v)} \text {. }
$$

It can be found that large-scale crack development will generate AE signals with low frequency. Meanwhile, Ohnaka and Mogi [36] analyzed the frequency characteristics of AE generated by both rocks under uniaxial compression, and they found that the proportion of low-frequency AE signals obviously increased when the rock was near destruction. They believed that this was related to the low-frequency 


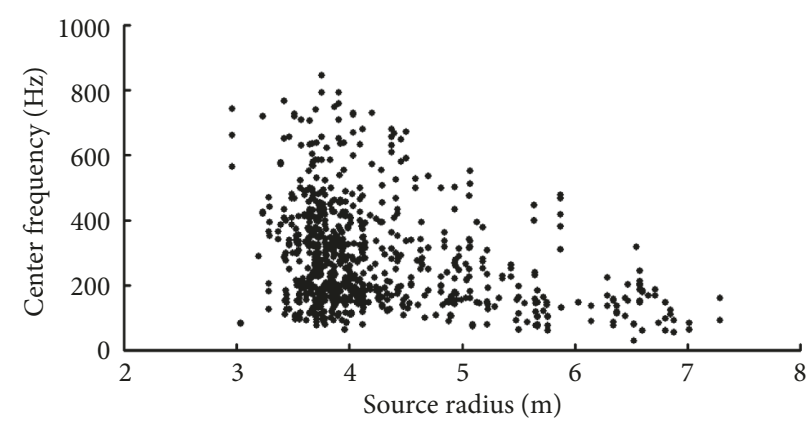

(a)

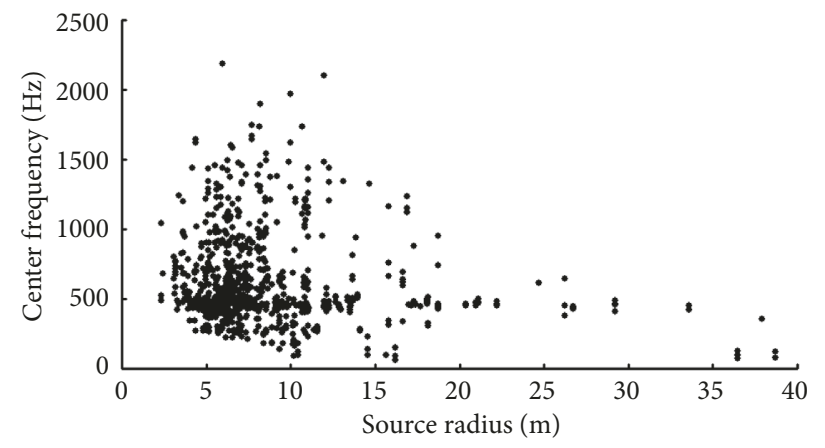

(c)

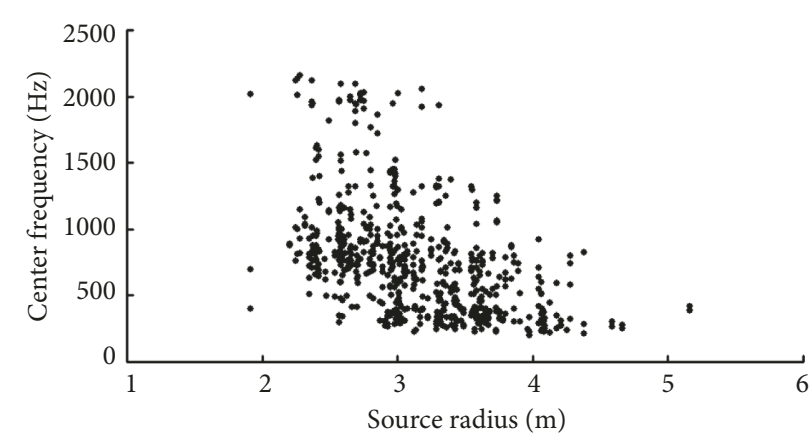

(b)

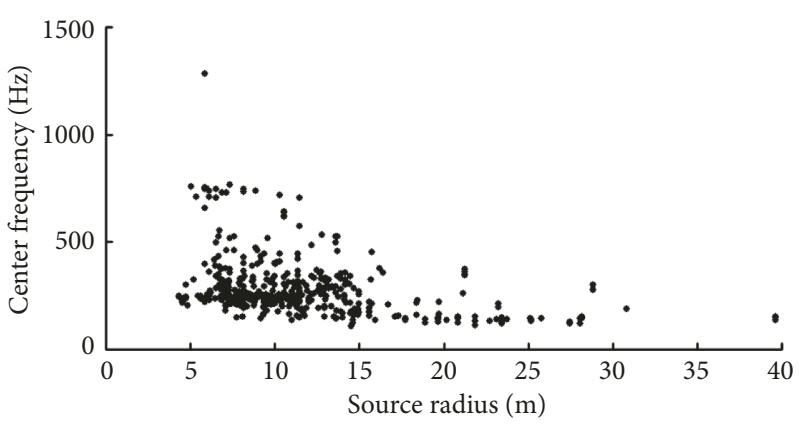

(d)

FIGURE 2: Relationship between source radius and frequency characteristic in each engineering project: (a) Jinping project during excavation, (b) Jinping project during impoundment, (c) Houziyan project, and (d) Baihetan project.

signal generated by the large cracks that occurred in the rock when rock was adjacent to failure. The similar AE regularities were also found in many rock $[9,12,37]$ and concrete [38] laboratory tests.

To analyze the frequency characteristics of MS signals in the engineering rock mass, the center frequencies of MS signals in Table 1 are selected as the frequency parameters. A statistical analysis of seismic source radius and center frequency of MS signals in the projects above is conducted. The statistical results are shown in Figure 2. Figure 2(a) shows that the crack scales of MS events occurred in the left bank slope of the Jinping project during excavation range from 2.9 to $7.3 \mathrm{~m}$ and mainly concentrated between 3.3 and $4.5 \mathrm{~m}$. Figure 2(b) shows that the crack scales of MS events in the left bank slope of the Jinping project during impoundment range from 1.9 to $5.2 \mathrm{~m}$ and concentrate between 2.2 and $4.4 \mathrm{~m}$. Comparing Figures 2(a) and 2(b), it can be deduced that the deformation of the left bank slope of the Jinping project during impoundment may be smaller than that during excavation. Compared with the excavation period, the frequency of MS signals during impoundment is distributed in a wider range. Figures 2(c) and 2(d) show the relationships between source radius and center frequency of MS signals obtained from the Houziyan project and Baihetan project during the statistical periods, respectively. Compared with slope engineering, the crack scales of MS events in underground powerhouses have a wider range. The source radiuses of MS events in the Houziyan project range from 2.3 to $38.7 \mathrm{~m}$ and concentrate between 3 and $11 \mathrm{~m}$. The source radiuses of MS events in the Baihetan project range from 4.3 to $39.7 \mathrm{~m}$ and concentrate between 5 and $15 \mathrm{~m}$.

Comparing the relationship between source radius and center frequency of each research object in Figure 2, the signal frequency has a wider distribution range when the fracture size of MS events is small in both slope engineering and underground powerhouse engineering. As the size of the rupture increases, the range of frequency distribution of MS signals gradually decreases. The high-frequency MS signals also gradually decrease, and the MS signals are characterized by low-frequency signals. These results are consistent with the phenomena observed in indoor AE tests by Ohnaka and Mogi [36].

The results above indicate that the frequency of $\mathrm{AE}$ signals is clearly related to the deformation of rock mass. Namely, as the fracture scale increases, the high-frequency component of $\mathrm{AE}$ signals decreases and the signals are characterized by low frequency. The failure of rock is the process of initiation, developing, transfixion, and forming a large-scale fracture of internal microfractures, eventually leading to macrodeformation and failure [12]. Prior to the rock failure, rock fracture is characterized by singlemicroscale random fractures and AE signals show highfrequency characteristics. When the rock is adjacent to failure, the microfractures continuously develop and interpenetrate to form large-scale fractures, and the signal frequency is characterized by low frequency. Therefore, the deformation behavior of rock mass with the scope of 


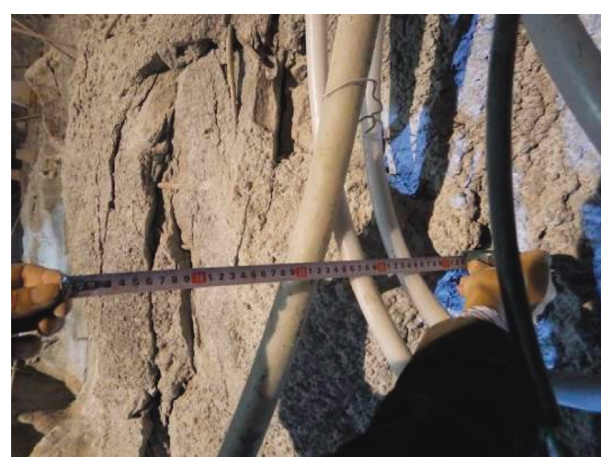

(a)

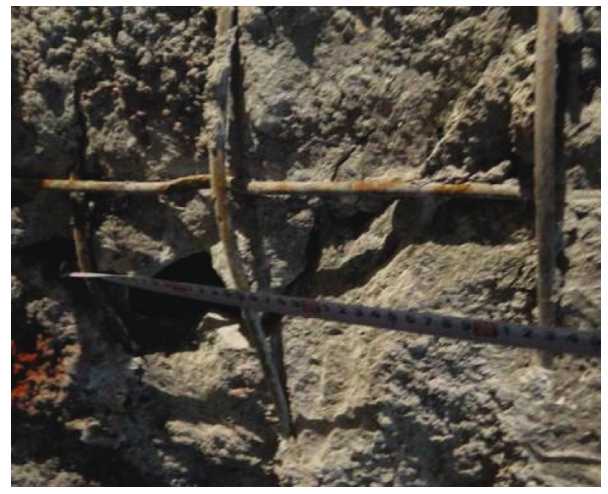

(c)

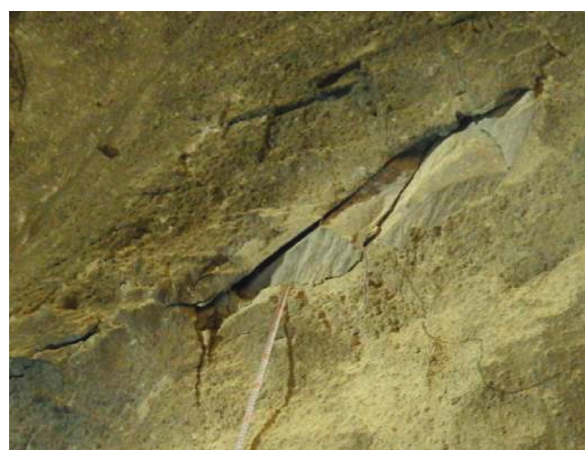

(b)

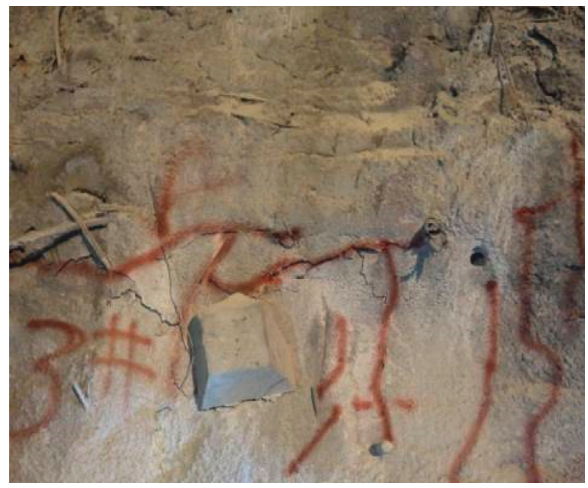

(d)

FIGURE 3: Rock mass failure photos taken in the underground caverns: (a) spalling of surrounding rock mass at downstream sidewall, (b) spalling of surrounding rock mass at upstream sidewall, (c) splitting and peeling off of surrounding rock mass in downstream sidewall, and (d) spalling of surrounding rock mass in the drainage tunnel.

interest can be investigated through analyzing the variation of frequency characteristics of MS events in the selected period, which will provide some references for stability evaluation of engineering rock mass.

\section{Case Study}

4.1. Project Overview. The Houziyan hydropower station, located in Kangding County, Ganzi Prefecture in Sichuan Province, is the ninth cascade hydropower station on upstream of the Dadu River. The underground plant system is located in the right bank slope. The dimensions of the main powerhouse are $219.50 \mathrm{~m}$ in length, $29.20 \mathrm{~m}$ in width, and $68.70 \mathrm{~m}$ in height. The elevation of the top arch is $1732.225 \mathrm{~m}$. The underground powerhouse is mainly buried horizontally at depths of 280 to $510 \mathrm{~m}$ and vertically at depths of 400 to $660 \mathrm{~m}$. It is a typical deep underground powerhouse with complex lithology and large-scale faults $[25,26]$.

Due to great depth, high geostress, and complex geologic structures, the problem of the multicavity effect is prominent. A large amount of rib spalling and rockbursts occurred subject to excavation unloading in the underground caverns of the Houziyan hydropower station (Figure 3). A real-time MS monitoring system was thus adopted to assess the stability of underground caverns during excavation. The installations of the MS monitoring system and previous achievements about the underground powerhouse of the Houziyan project can be referred to Li et al. [25, 26].

4.2. Correlation between MS Events Accumulation and Surrounding Rock Mass Deformation. Figure 4 shows the absolute displacement curves of the multipoint extensometers $\mathrm{M}_{\mathrm{XZ}}^{6}$ 1-2 and $\mathrm{M}_{\mathrm{CF}}^{4}$ 3-8 installed between omnibus bar caves $\# 1$ and \#3 in the downstream of main powerhouse. More than $10 \mathrm{~mm}$ displacement of multipoint extensometers $\mathrm{M}^{6}{ }_{\mathrm{XZ}} 1-2$ and $\mathrm{M}_{\mathrm{CF}}^{4}$ 3-8 occurred on the beginning of December 2013 and January 2014, respectively. Combined with the construction dynamic condition, the phenomenon can be interpreted that the deformation was primarily attributed by the excavation of layer V and VI of the main powerhouse. The excavation exposure is shown in Figure 5.

The MS activities characteristics of the main powerhouse between November 26 and December 14, 2013, and between December 23 and January 10, 2014, are shown in Figure 6, respectively, which corresponds to the two stages of surrounding rock mass deformation in Figure 4(b). It can be found that MS events concentrated near the region of multipoint extensometer $\mathrm{M}_{\mathrm{CF}}^{4}$ 3-8 obviously and showed great consistence in temporal distribution. The phenomenon demonstrates that MS activity can reflect the visual deformation measured by multipoint extensometers 


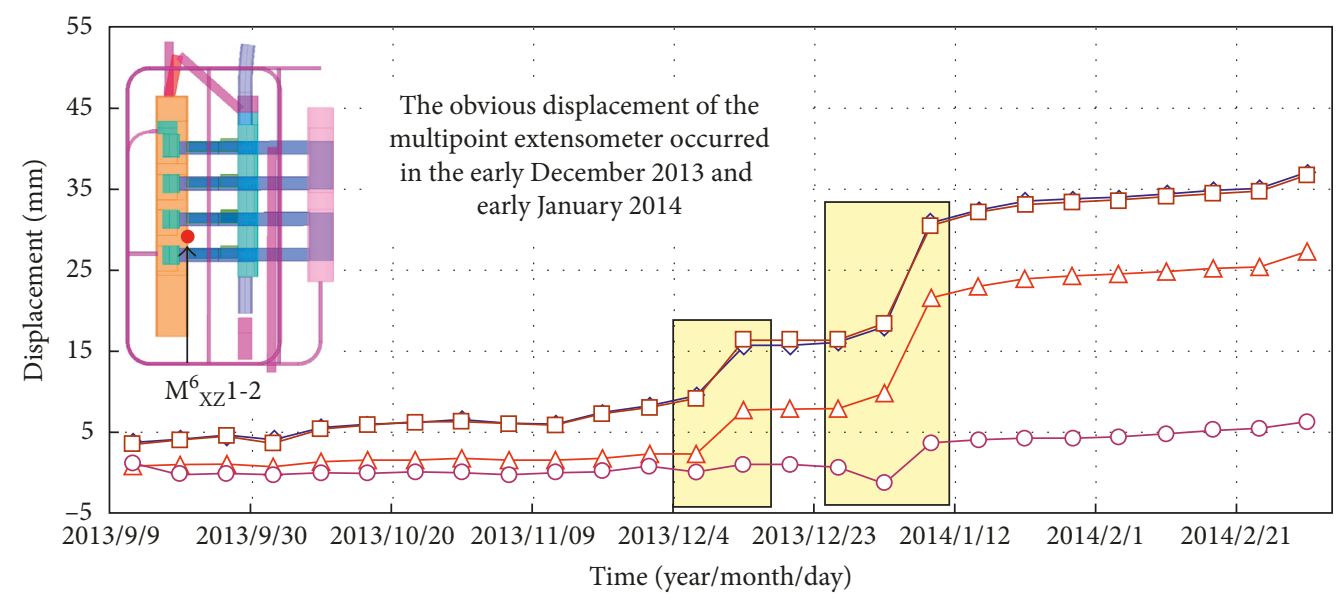

$$
\begin{aligned}
& \prec-\text { Orifice } \\
& -\square 2 \mathrm{~m}
\end{aligned}
$$

$$
\triangle 15 \mathrm{~m}
$$$$
\text { -O- } 24 \mathrm{~m}
$$

(a)

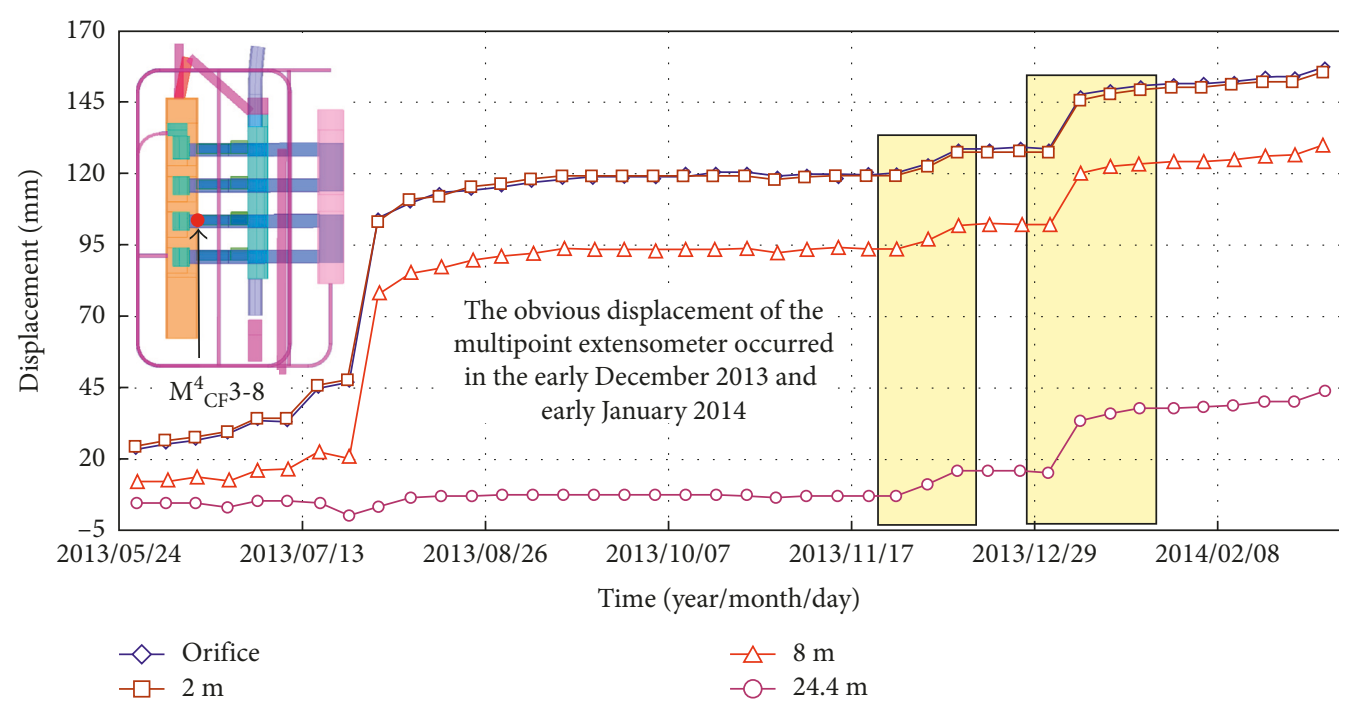

(b)

FIgURE 4: Monitoring data of multipoint extensometers: (a) the displacement process curve of $\mathrm{M}^{6} \mathrm{XZ}^{1-2}$ and (b) the displacement process curve of $\mathrm{M}_{\mathrm{CF}}^{4} 3-8$.

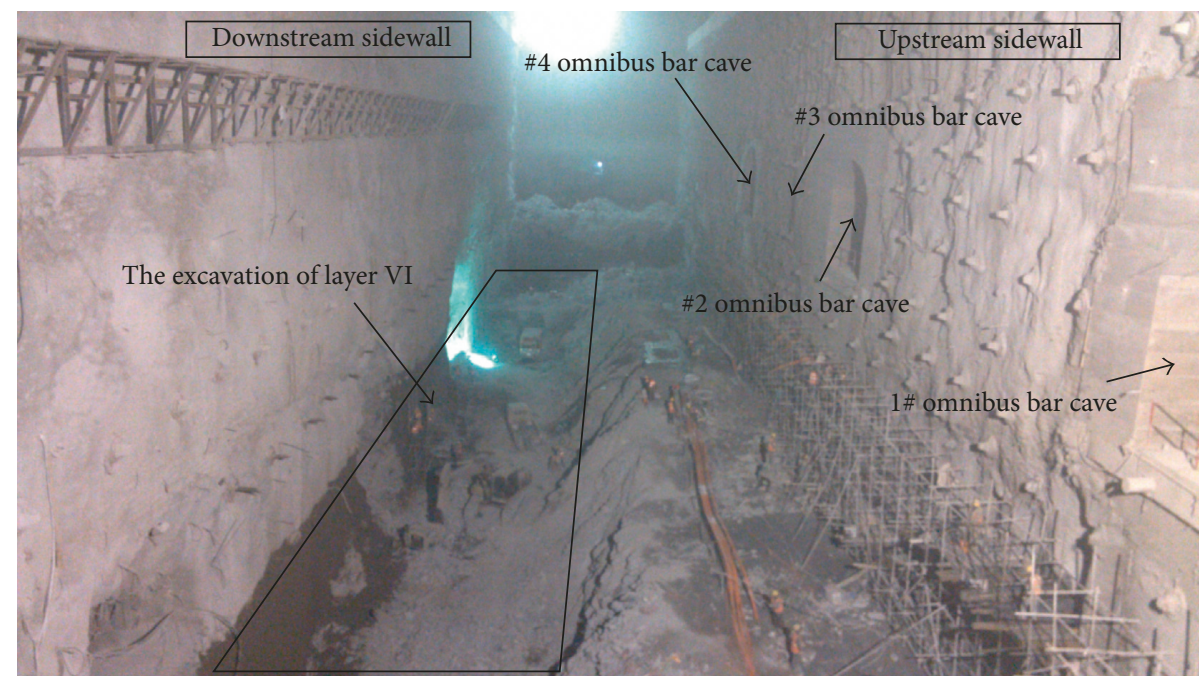

Figure 5: The excavation of layer VI (the photo was taken on December 21, 2013). 


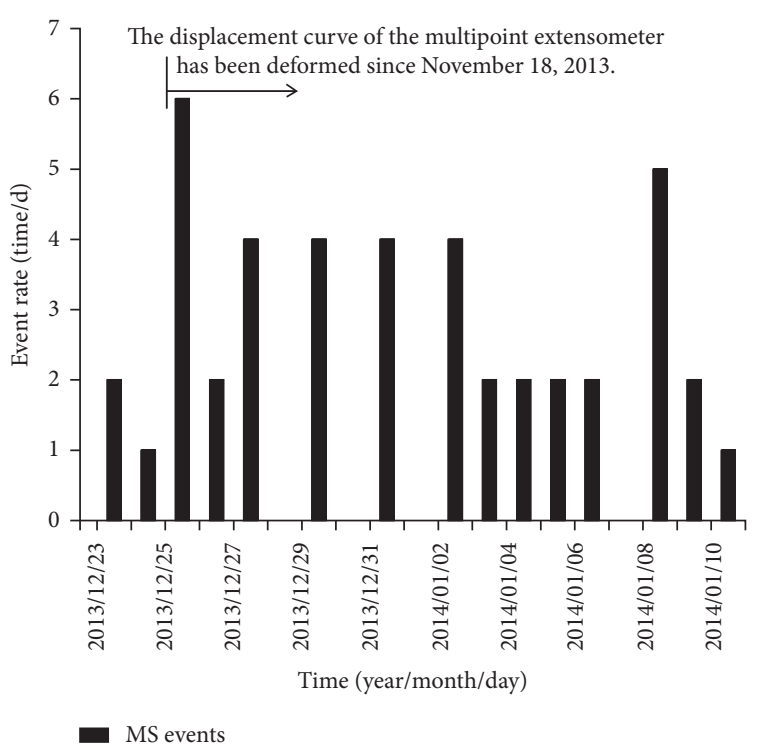

(a)

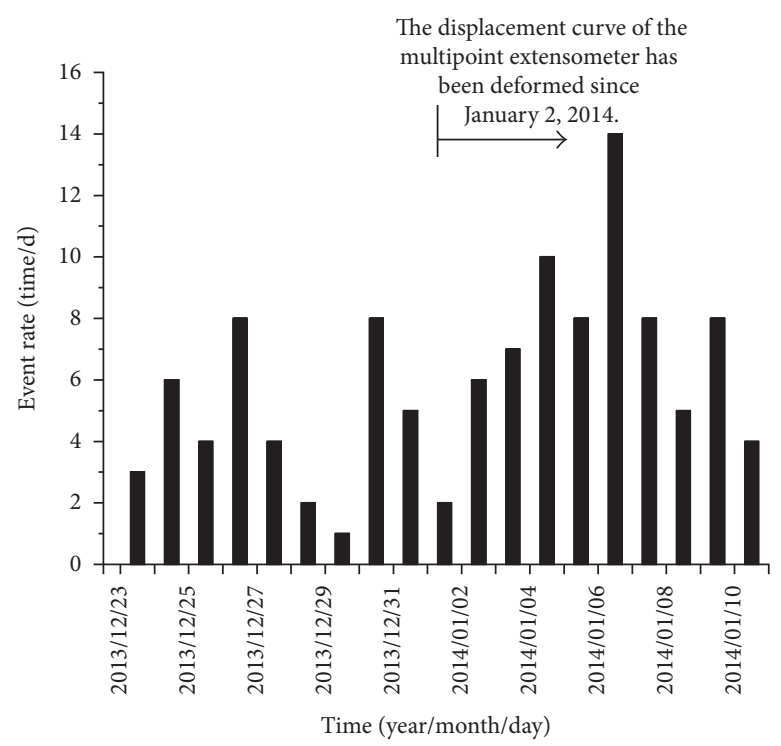

MS events

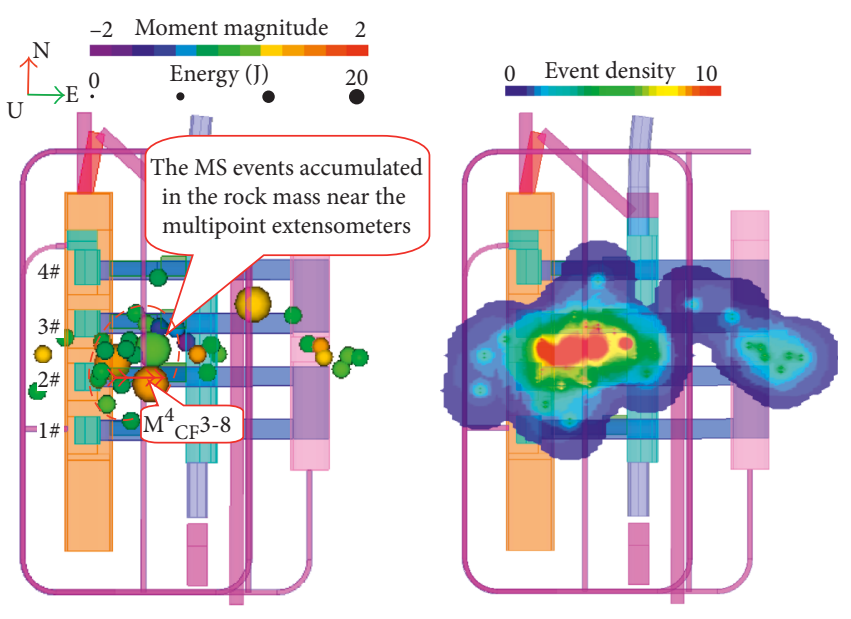

(b)

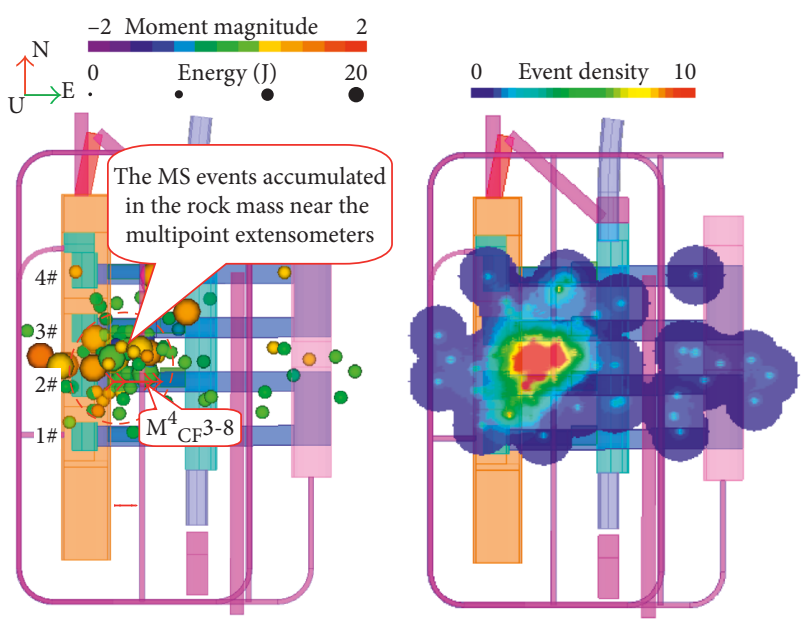

(d)

FIGURE 6: MS events occurred during the two stages of surrounding rock mass deformation: (a) temporal distribution of MS events between November 26 and December 14, 2013, (b) spatial distribution of MS events and their corresponding density nephogram between November 26 and December 14, 2013, (c) temporal distribution of MS events between December 23 and January 10, 2014, and (d) spatial distribution of MS events and their corresponding density nephogram between December 23 and January 10, 2014.

accurately. Namely, the deformation of surrounding rock mass usually lags behind the concentration of MS events. Therefore, the variation of MS events can be regarded as the basis for judging the deformation of surrounding rock mass.

\subsection{Frequency Evolution Characteristics of MS Signals during} Deformation Processes of Surrounding Rock Mass. In the deformation period of surrounding rock mass above, the MS events accumulated in surrounding rock mass near multipoint extensometers are selected as a research object. The MS signals are processed based on the ST waveform processing method, and the frequency variation characteristics during the deformation processes of multipoint extensometers are also analyzed. Figure 7 shows temporal distribution regularities of the center frequency of MS events concentrated near multipoint extensometers, and the displacement process curve of multipoint extensometers $\mathrm{M}_{\mathrm{CF}}^{4} 3-8$, respectively. From the displacement curve of multipoint extensometer $\mathrm{M}_{\mathrm{CF}}^{4}$ 3-8 in Figure $7(\mathrm{~b})$, surrounding rock mass deformation occurred two times in the selected period, namely, between November 28 and December 12, 2013, and between January 2 to 9, 2014, respectively. Figure 7(a) shows 


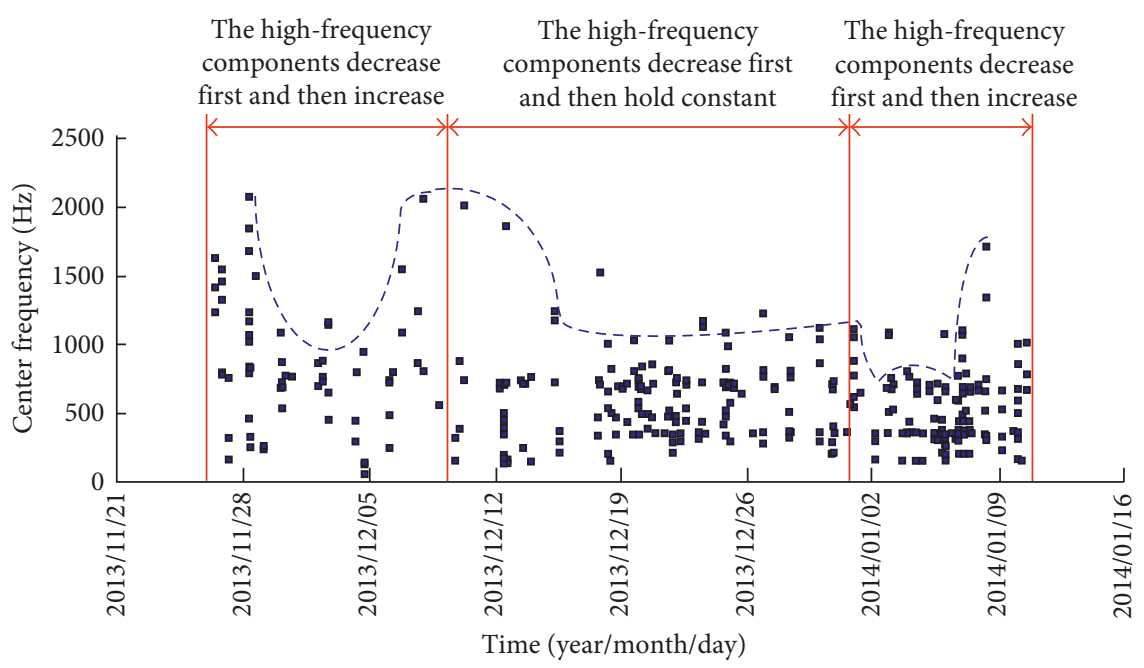

(a)

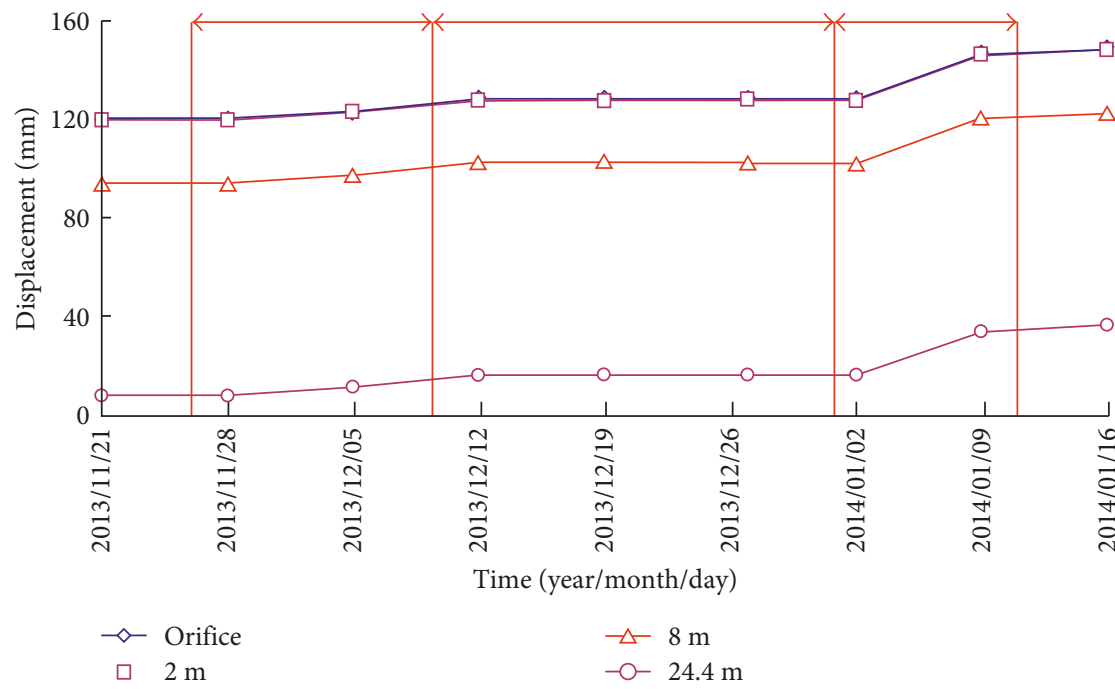

(b)

FIgURE 7: Temporal distribution regularities of the center frequency of MS events (a) and the displacement process curve of multipoint extensometers $\mathrm{M}_{\mathrm{CF}}^{4}$ 3-8 (b).

that the high-frequency components of MS signals underwent two ascending phases and three dropping phases during the selected period. Combined with the results of surrounding rock mass deformation, the high-frequency components of center frequencies of MS signals in the concentrated zone began to decrease on November 28, 2013. The results in Section 3.2 show that the decrease of highfrequency signals indicates the increase of source rupture scale. Coincidentally, surrounding rock mass began to deform on November 28, 2013. Afterwards, several highfrequency signals appeared, the ratio of high-frequency components began to increase, but there were still a large number of high-frequency components missing. Since December 8, 2013, the high-frequency components of MS signals in the concentrated zone reduced again and then kept constant. The high-frequency components reduced again on December 31,2014, which indicated a further increase in the source rupture scale. Coincidentally, obvious deformation occurred on January 2, 2014, as shown in Figure 7(b). Since January 6, 2014, the high-frequency components of MS signals increased sporadically, and the center frequency tends to rise. Correspondingly, the displacement curve of multipoint extensometer flattens out after January 9, 2014.

During the two deformation processes of surrounding rock mass as shown in Figure 8(b), the high-frequency components of MS signals all went through the evolutionary process of reducing first and then increasing. This indicates that the frequency variation of MS signals corresponds well with surrounding rock mass deformation. Therefore, the deformation process of surrounding rock mass can be revealed by analyzing the frequency variation characteristics of MS signals in the concentrated zone in the selected period.

The distribution range of the dominant frequency of MS signals in the concentrated zone during the two deformation stages in Figure 6 is equally divided into several bands. The 


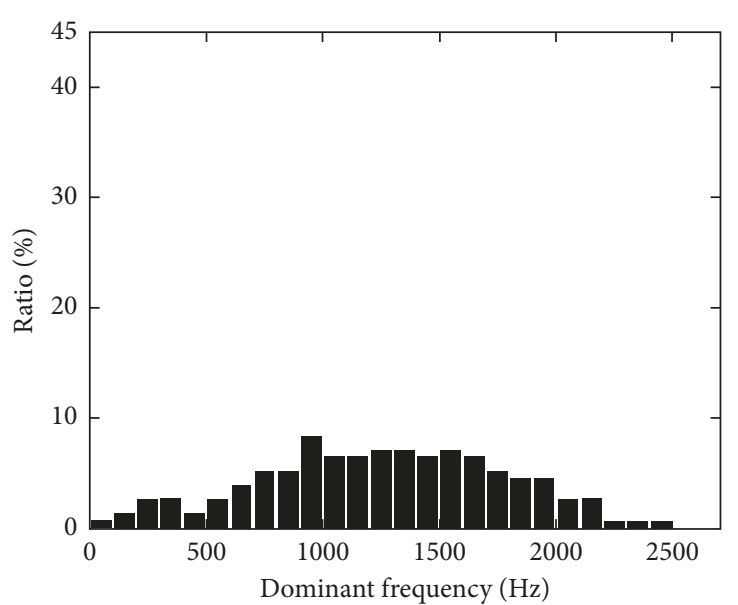

$26 \sim 28 / 11 / 2013$

(a)

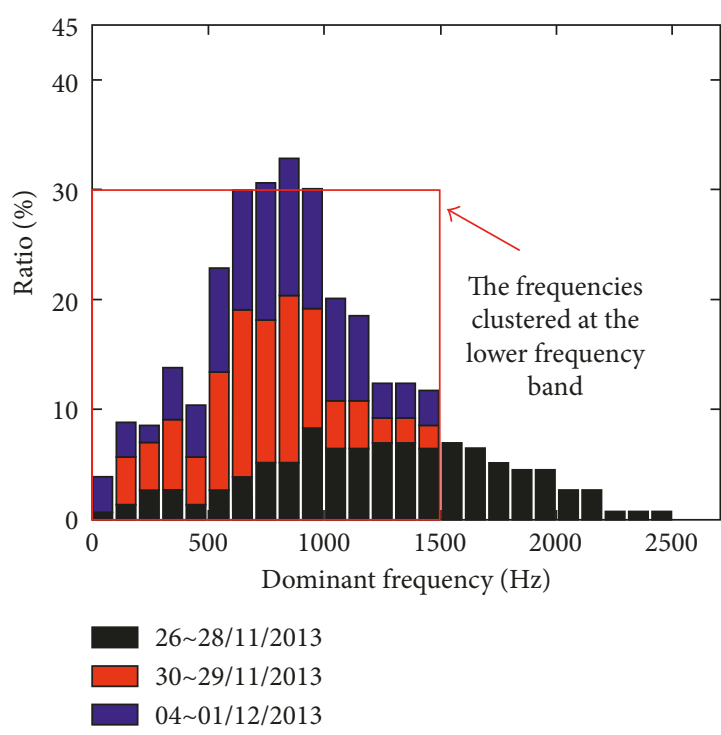

(c)

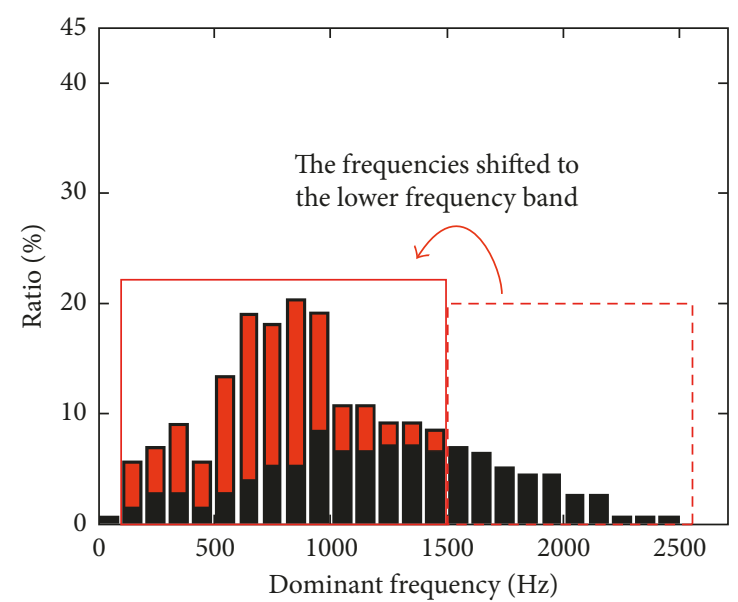

26 28/11/2013

29 30/11/2013

(b)

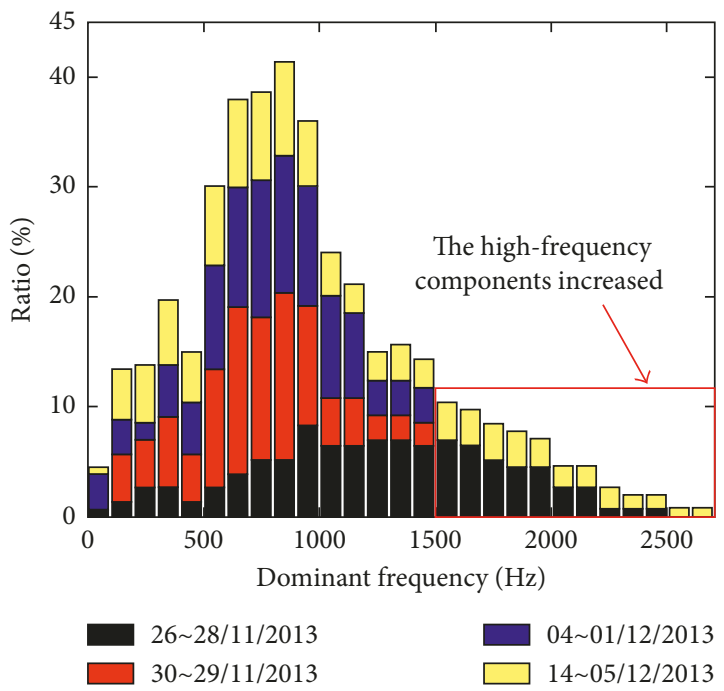

(d)

Figure 8: The accumulative variation of dominant frequency of MS signals: (a) date time: 26/11/2013 27/11/2013, (b) date time: 26/11/2013 30/11/2013, (c) date time: 26/11/2013 4/12/2013, and (d) date time: 26/11/2013 14/12/2013.

percentage of MS signals components in different ranges is statistically analyzed. The accumulated variation regularities of the dominant frequency in the two deformation stages are obtained as shown in Figures 8 and 9, respectively. It can be found from Figure 8 that the low-frequency components of MS signals obviously increased between November 28 and 30,2013 , and the phenomenon of frequency transferring to low frequency occurred, compared to that between November 26 and 27, 2013. Correspondingly, an obvious deformation of surrounding rock mass appeared during the selected period as shown in Figure 8(b). The components of MS signals were further transferred to lower frequency band between December 1 and 4, 2013. However, the highfrequency components of MS signals increased between December 5 and 14, 2013. Coincidently, the surrounding rock mass deformation continued to develop on December
5, 2013, and ended on December 12, 2013, as shown in Figure 7(b). It can be found from Figure 9 that the lowfrequency components of MS signals increased and the highfrequency components decreased, accompanied by the frequency changing from high frequency to low frequency. This phenomenon occurred during the period between December 27, 2013, and January 1, 2014, before an obvious deformation appeared. The MS signals with low frequency continued to occur during the period between January 2 and January 6, 2014. Then, the high-frequency components of MS signals increased between January 7 and 10, 2014. These phenomena can verify the results of Section 3.2 very well. Consequently, prior to obvious deformation of surrounding rock mass, the frequency of MS signals usually shift from high frequency to low frequency. The decrease of MS signal frequency in the selected concentrated zone can be thus regarded 


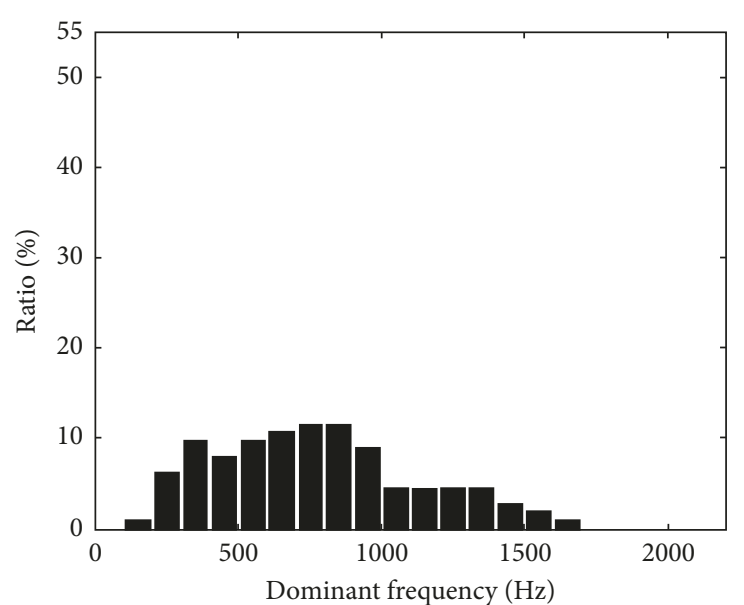

$23 \sim 26 / 12 / 2013$

(a)

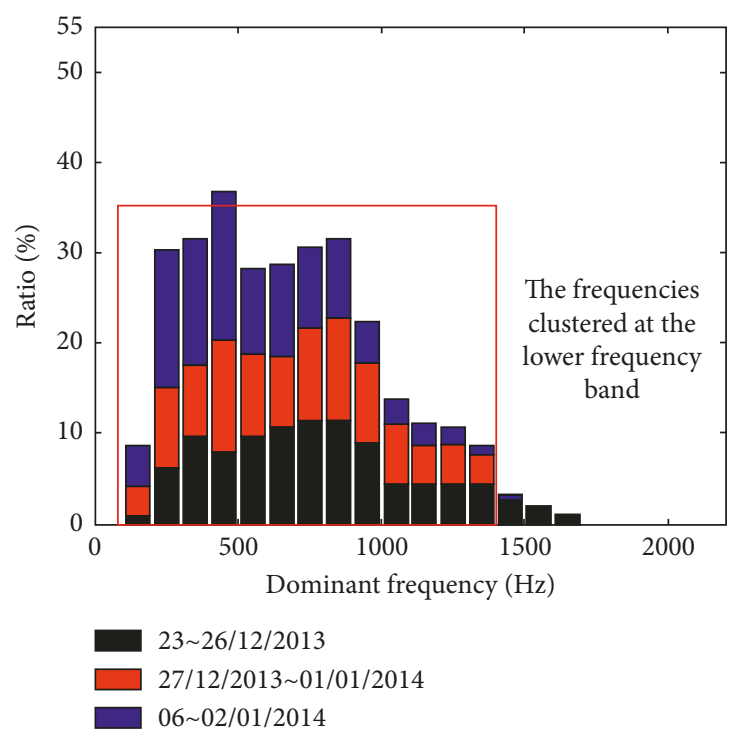

(c)

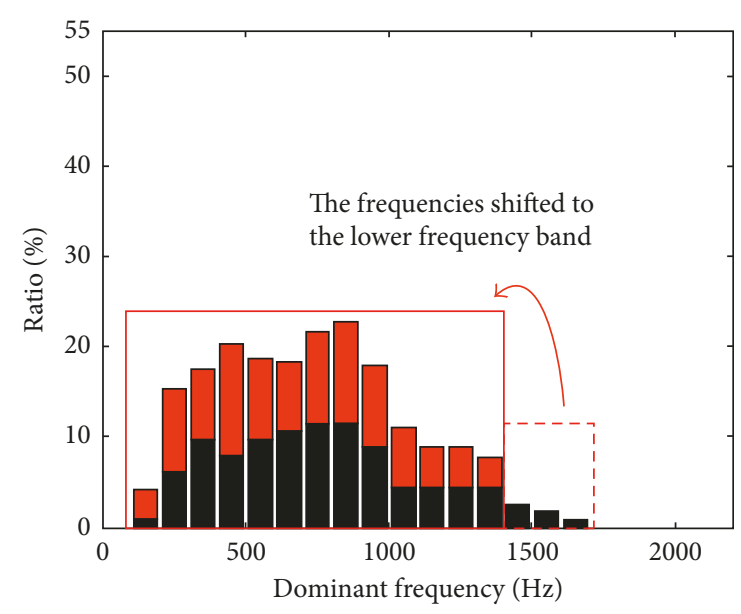

23 26/12/2013

27/12/2013 01/01/2014

(b)

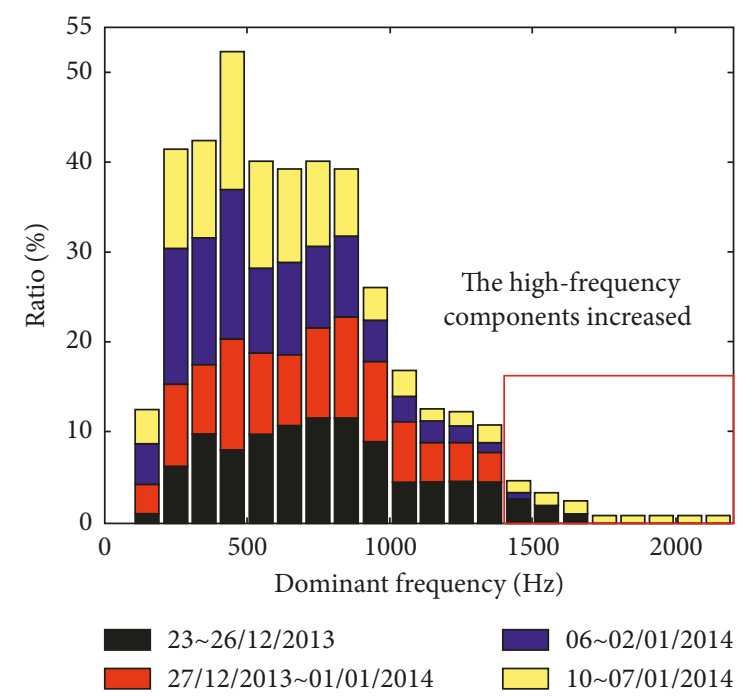

(d)

FIgURE 9: The accumulative variation of dominant frequency of MS signals: (a) date time: 23/12/2013 26/12/2013, (b) date time: 23/12/2013 1/1/2014, (c) date time: 23/12/2013 6/1/2014, and (d) date time: 23/12/2013 10/1/2014.

as a precursor for deformation and failure of surrounding rock mass.

\section{Conclusions}

(1) Compared with the conventional methods, the ST method can provide intuitive time-frequency characteristics without selecting the window function and analysis scale. Moreover, ST can selfadaptively adjust the analysis time width according to the signals and can accurately describe the temporal variation characteristics of nonstationary signals such as MS signals.

(2) The correlation between source radius and frequency characteristics of MS signals is investigated based on numerous MS data from three large-scale hydropower projects. The correlation between fracture scale of rock mass and frequency of MS signals is also revealed. The results demonstrate that high-frequency components of the MS signal decrease, and the signals are characterized by low frequency when the rupture scale increases.

(3) A case study is conducted based on the results of MS monitoring and multipoint extensometers results obtained from the underground cavern of the Houziyan project. The results demonstrate that the frequency variation of MS signals corresponds well with the deformation process of surrounding rock mass. The high-frequency component of MS signals decreases at first and then increases during the deformation processes of surrounding rock mass. Prior to obvious deformation of surrounding rock mass, the phenomenon of MS signals shifting from high 
frequency to low frequency usually occurs. Therefore, the decrease of MS signal frequency can be regarded as a precursor of macroscopic deformation failure of surrounding rock masses, which can provide some references for stability evaluation and macroscopic deformation failure forecasting of surrounding rock mass.

\section{Data Availability}

The authors declare that all the data supporting the conclusions of the present study can be obtained from the corresponding author.

\section{Conflicts of Interest}

The authors declare that there are no conflicts of interest.

\section{Authors' Contributions}

Nuwen $\mathrm{Xu}$ proposed the idea of correlation analysis between fracture scale and frequency of MS signals. Peiwei Xiao, Peng Jiang, and Biao Li processed and analyzed the abundant MS data. Peiwei Xiao, Bo Qian, and Nuwen Xu wrote the paper.

\section{Acknowledgments}

The authors are grateful for the financial support from the National Natural Science Foundation of China (no. 51679158) and the National Program on Key Basic Research Project (no. 2015CB057903).

\section{References}

[1] X. L. Lei and T. S. Satoh, "Indicators of critical point behavior prior to rock failure inferred from pre-failure damage," Tectonophysics, vol. 431, no. 1-4, pp. 97-111, 2007.

[2] J. F. Labuz and L. Biolzi, "Experiment with rock: remarks on strength and stability issues," International Journal of Rock Mechanics and Mining Sciences, vol. 44, no. 4, pp. 525-537, 2007.

[3] X. L. Lei, K. Masuda, O. Nishizawa et al., "Detailed analysis of acoustic emission activity during catastrophic fracture of faults in rock," Journal of Structural Geology, vol. 26, no. 2, pp. 247-258, 2004.

[4] A. Terchi and Y. H. J. Au, "Acoustic emission signal processing," Measurement and Control, vol. 34, no. 8, pp. 240244, 2001.

[5] R. Zhang, H. P. Xie, J. F. Liu et al., "Experimental study on acoustic emission characteristics of rock failure under uniaxial multilevel loadings," Chinese Journal of Rock Mechanics and Engineering, vol. 25, no. 12, pp. 2584-2588, 2006.

[6] S. L. Li, X. G. Yin, Y. J. Wang et al., "Studies on acoustic emission characteristics of uniaxial compressive rock failure," Chinese Journal of Rock Mechanics and Engineering, vol. 23, no. 15, pp. 2499-2503, 2004.

[7] Y. H. Li, J. P. Liu, X. D. Zhao et al., "Study on $b$-value and fractal dimension of acoustic emission during rock failure process," Rock and Soil Mechanics, vol. 30, no. 9, pp. 25592563, 2009.
[8] H. G. Ji, T. S. Zhang, Z. Y. Zhang et al., "Analysis on the acoustic emission parameters for nondestructive testing," Nondestructive Testing, vol. 23, no. 7, pp. 289-291, 2001.

[9] M. C. He, F. Zhao, Y. Zhang et al., "Feature evolution of dominant frequency components in acoustic emissions of instantaneous strain-type granitic rockburst simulation tests," Rock and Soil Mechanics, vol. 36, no. 1, pp. 1-8, 2015.

[10] Y. X. Xiao, X. T. Feng, B. R. Chen et al., "Evolution of frequency spectrum during instant rockbursts in deep inoculation tunnel," Rock and Soil Mechanics, vol. 36, no. 4, pp. 1127-1134, 2015.

[11] J. L. Miao, M. C. He, D. J. Li et al., "Acoustic emission characteristics of granite under strain rockburst test and its micro-fracture mechanism," Chinese Journal of Rock Mechanics and Engineering, vol. 28, no. 8, pp. 1593-1603, 2009.

[12] M. C. He, J. L. Miao, and J. L. Feng, "Rock burst process of limestone and its acoustic emission characteristics under truetriaxial unloading conditions," International Journal of Rock Mechanics and Mining Sciences, vol. 47, no. 2, pp. 286-298, 2010.

[13] C. P. Lu, L. M. Dou, X. R. Wu et al., "Experimental and empirical research on frequency-spectrum evolvement rule of rockburst precursory microseismic signals of coal-rock," Chinese Journal of Rock Mechanics and Engineering, vol. 27, no. 3, pp. 519-525, 2008.

[14] J. P. Li, Z. X. Yu, C. B. Zhou et al., "Experimental study on acoustic emission characteristics of rock concerning hydromechanical coupling," Chinese Journal of Rock Mechanics and Engineering, vol. 25, no. 3, pp. 492-498, 2006.

[15] J. W. Neuberg, H. Tuffen, L. Collier et al., "The trigger mechanism of low-frequency earthquakes on Montserrat," Journal of Volcanology and Geothermal Research, vol. 153, no. 1, pp. 37-50, 2006.

[16] C. P. Lu, L. M. Dou, H. Liu et al., "Case study on microseismic effect of coal and gas outburst process," International Journal of Rock Mechanics and Mining Sciences, vol. 53, pp. 101-110, 2012.

[17] G. Y. Zhao, Q. L. Deng, and J. Ma, "Recognition of mine microseismic signals based on FSWT time-frequency analysis," Chinese Journal of Geotechnical Engineering, vol. 37, no. 2, pp. 306-312, 2015.

[18] H. P. Liu and D. D. Kosloff, "Numerical evaluation of the Hilbert transform by the Fast Fourier Transform (FFT) technique," Geophysical Journal International, vol. 67, no. 3, pp. 791-799, 1981.

[19] W. Lu and F. Li, "Seismic spectral decomposition using deconvolutive short-time Fourier transform spectrogram," Geophysics, vol. 78, no. 2, pp. 43-51, 2013.

[20] S. Sinha, P. S. Rout, P. D. Anno, and J. P. Castagna, "Spectral decomposition of seismic data with continuous-wavelet transform," Geophysics, vol. 70, no. 6, pp. 19-25, 2008.

[21] R. G. Stockwell, L. Mansinha, R. P. Lowe et al., "Localization of the complex spectrum: the S transform," IEEE Transactions on Signal Processing, vol. 44, no. 4, pp. 998-1001, 1996.

[22] M. W. Zhang, H. Shimada, T. Sasaoka et al., "Seismic energy distribution and hazard assessment in underground coal mines using statistical energy analysis," International Journal of Rock Mechanics and Mining Sciences, vol. 64, pp. 192-200, 2013.

[23] N. W. Xu, C. A. Tang, L. C. Li et al., "Microseismic monitoring and stability analysis of the left bank slope in Jinping first stage hydropower station in southwestern China," International Journal of Rock Mechanics and Mining Sciences, vol. 48, no. 6, pp. 950-963, 2011. 
[24] N. W. Xu, F. Dai, Z. Zhou et al., "Microseismicity and its time-frequency characteristics of the left bank slope at the Jinping first-stage hydropower station during reservoir impoundment," Environmental Earth Sciences, vol. 75, no. 7, pp. 1-17, 2016.

[25] B. Li, F. Dai, N. W. Xu et al., "Microseismic monitoring system and its engineering applications of deep-buried underground powerhouse," Chinese Journal of Rock Mechanics and Engineering, vol. 33, no. 1, pp. 3375-3383, 2014.

[26] N. W. Xu, T. B. Li, F. Dai et al., "Microseismic monitoring and stability evaluation for the large scale underground caverns of Houziyan hydropower station in southwest china," Engineering Geology, vol. 188, pp. 48-67, 2015.

[27] F. Dai, B. Li, N. W. Xu et al., "Deformation forecasting and stability analysis of large-scale underground powerhouse caverns from microseismic monitoring," International Journal of Rock Mechanics and Mining Sciences, vol. 86, pp. 269-281, 2016.

[28] J. N. Brune, "Tectonic stress and the spectra of seismic shear waves from earthquakes," Journal of Geophysical Research, vol. 75, no. 26, pp. 4997-5009, 1970.

[29] R. Madariaga, "Dynamics of an expanding circular fault," Bulletin of the Seismological Society of America, vol. 66, no. 3, pp. 639-666, 1976.

[30] M. Cai, P. K. Kaiser, and C. D. Martin, "A tensile model for the interpretation of microseismic events near underground openings," Pure and Applied Geophysics, vol. 153, no. 1, pp. 67-92, 1998.

[31] C. I. Trifu, T. I. Urbancic, and R. P. Young, "Source parameters of mining-induced seismic events: an evaluation of homogeneous and inhomogeneous faulting models for assessing damage potential," Pure and Applied Geophysics, vol. 145 , no. 1 , pp. 3-27, 1995.

[32] D. J. Andrews, "Objective determination of source parameters and similarity of earthquakes of different sizes," Earthquake Source Mechanics, vol. 37, no. 6, pp. 259-267, 1986.

[33] M. Cai, P. K. Kaiser, H. Morioka et al., "FLAC/PFC coupled numerical simulation of AE in large-scale underground excavations," International Journal of Rock Mechanics and Mining Sciences, vol. 44, no. 4, pp. 550-564, 2007.

[34] M. Ohnaka, "A physical basis for earthquakes based on the elastic rebound model," Bulletin of the Seismological Society of America, vol. 66, no. 2, pp. 433-451, 1976.

[35] N. A. Haskell, "Total energy and energy spectral density of elastic wave radiation from propagating faults," Bulletin of the Seismological Society of America, vol. 54, no. 6A, pp. 18111841, 1964.

[36] M. Ohnaka and K. Mogi, "Frequency characteristics of acoustic emission in rocks under uniaxial compression and its relation to the fracturing process to failure," Journal of Geophysical Research, vol. 87, no. B5, pp. 3873-3884, 1982.

[37] J. Xu, R. H. Yang, J. G. Zhang et al., "A preliminary study on precursors of strong fracture in brittle material specimens," Chinese Journal of Geophysics, vol. 54, no. 9, pp. 2283-2292, 2011.

[38] D. G. Aggelis, "Classification of cracking mode in concrete by acoustic emission parameters," Mechanics Research Communications, vol. 38, no. 3, pp. 153-157, 2011. 


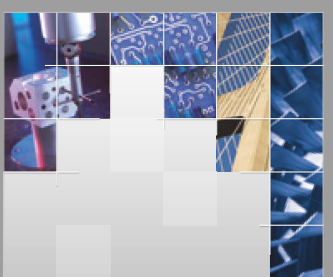

\section{Enfincering}
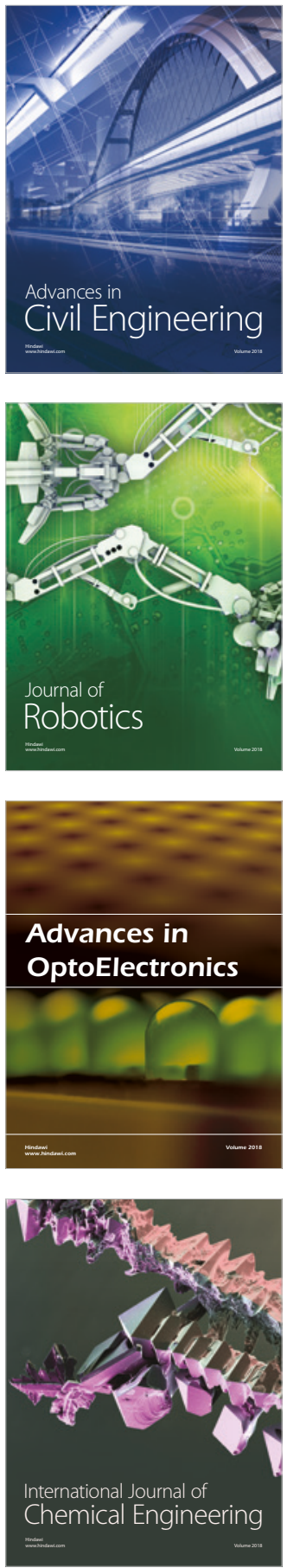

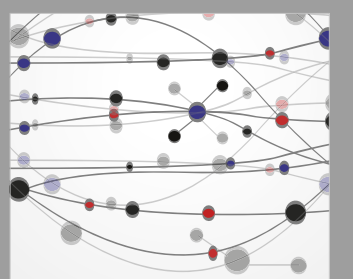

\section{Rotating \\ Machinery}

The Scientific World Journal

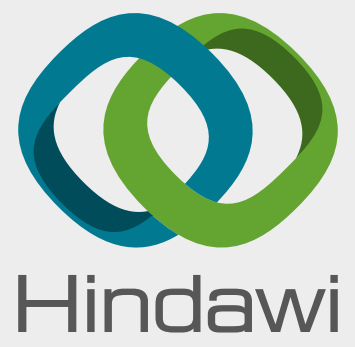

Submit your manuscripts at

www.hindawi.com
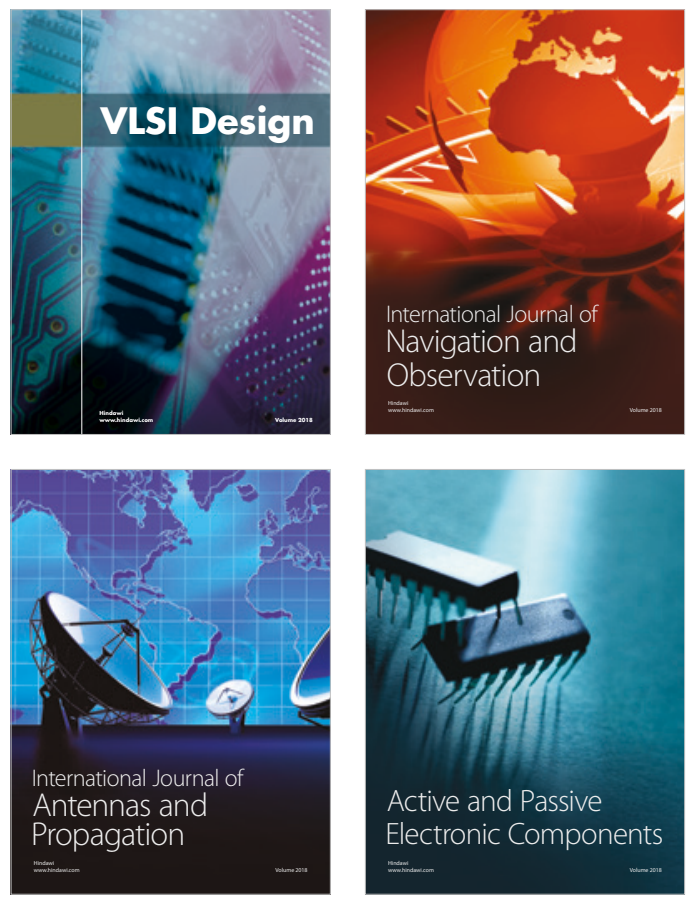
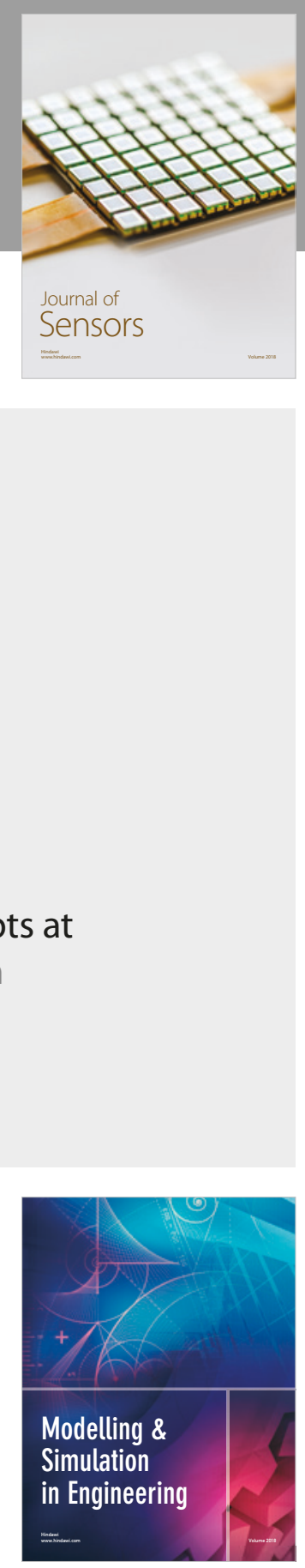

\section{Advances \\ Multimedia}
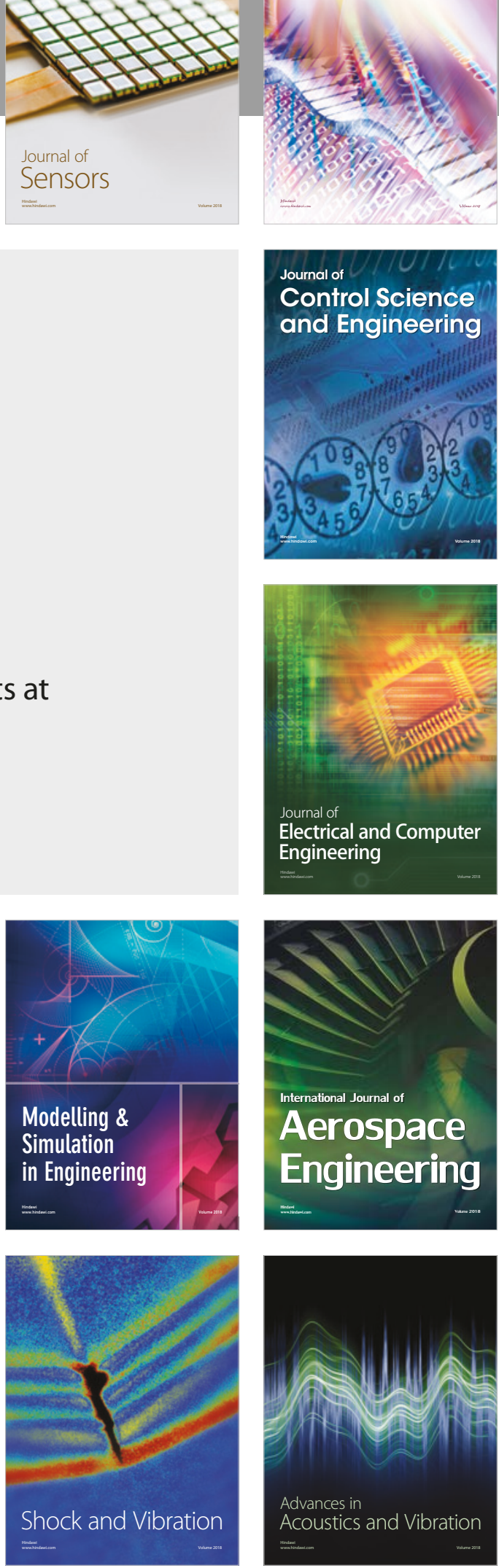